\title{
Predictors of Postpartal Retained Products of Conception
}

\author{
FABINSHY THANGARAJAH ${ }^{1,2}$, MAGDALENA BRUNNER ${ }^{1}$, CAROLINE PAHMEYER ${ }^{1}$, JULIA CAROLINE RADOSA ${ }^{3}$, \\ CHRISTIAN EICHLER ${ }^{1,2}$, SEBASTIAN LUDWIG $^{1}$, BERND MORGENSTERN ${ }^{1}$ and PETER MALLMANN ${ }^{1}$ \\ ${ }^{1}$ Department of Obstetrics and Gynecology, University Hospital Cologne and Medical Faculty, Cologne, Germany; \\ ${ }^{2}$ Breast Center, University Hospital Cologne, Cologne, Germany; \\ ${ }^{3}$ Clinic for Gynecology, Obstetrics and Reproductive Medicine, \\ Saarland University Medical Center, Homburg, Germany
}

\begin{abstract}
Background: Retention of products of conception (RPOC) following delivery is rare. Clinicians often have the impression that a high proportion of patients with sonographically suspected RPOC following surgery have a negative histopathology. Hence, we aimed to report our singlecenter experience with suspected RPOC and histopathological outcome after surgery. Patients and Methods: In this retrospective analysis, patients who underwent surgery due to suspected postpartum RPOC were analyzed for potential predictive clinical and sonographic parameters. Results: A total of 32 patients with histopathologically-confirmed RPOC were compared with 21 patients with a negative histopathological report for RPOC. Endometrial hyperechogenic mass and clinical parameters such as pain, fever and bleedings were not predictive for RPOC. Increased age $(p=0.001)$ and vaginal delivery $(p=0.040)$ were significantly associated with RPOC. Conclusion: Clinical presentation alone is not predictive for RPOC. Vaginal delivery and younger age seem to be a risk factor and therefore have to be considered in patients with suspected RPOC.
\end{abstract}

Retention of products of conception (RPOC) following delivery is rare, with an incidence of $1-6 \%(1,2)$, which seems to depend on the gestational age of the pregnancy, with the highest frequency after second-trimester delivery or termination of pregnancy (3). Usually patients present with vaginal bleeding $(2,4)$, pain, infection or hypomenorrhea and infertility due to intrauterine adhesions $(2,5,6)$.

This article is freely accessible online.

Correspondence to: Dr. med. Fabinshy Thangarajah, University Hospital Cologne, Department of Obstetrics and Gynecology, Medical Faculty, Kerpener Str. 34, 50931 Cologne, Germany. Tel: +49 22147886545, Fax: +49 22147886546, e-mail: Fabinshy. Thangarajah@uk-koeln.de

Key Words: Delivery, RPOC, curretage.
Asymptomatic patients are diagnosed with RPOC in routine postpartum examinations (2).

The diagnosis of RPOC by transvaginal ultrasonography is generally based on the detection of increased endometrial thickness and volume. Furthermore, the presence of hyperechoic material inside the cavity, or complex endometrial fluid also play a role in diagnosis of RPOC (7-9).

It is known that RPOC has variable appearance in sonography, with an overall reported sensitivity of $44-85 \%$ and specificity of $88-94 \%$ (10-15). Clinicians often have the impression that a high proportion of patients with sonographically suspected RPOC following surgery have a negative histopathology.

Hence, we aimed to report our single-center experience with suspected RPOC and histopathological outcome after surgery. Of special interest was the assessment of predictors of RPOC and diagnostic accuracy of ultrasound, and whether surgery might be avoided in selected patients.

\section{Patients and Methods}

In this retrospective analysis, patients who underwent surgery due to suspected postpartum RPOC were included. Patients were treated at the Department of Gynecology and Obstetrics of the University Hospital Cologne.

Patient characteristics, histopathological data and potential predictors were assessed.

The medical records of all patients were obtained from the comprehensive electronic hospital information system $\left(\right.$ ORBIS ${ }^{\circledR}$ OpenMed; AGFA HealthCare NV, Mortsel, Belgium) and patient records of the university hospital. The clinical and histological characteristics of each patient and each surgical procedure were also extracted from the patient records. Data collected for the study included patient demographics, gynecological history, clinical presentation and sonographic evaluation. Data also included gestational age, delivery type (vaginal or caesarean), multiple pregnancies, presence of postpartum hemorrhage and histopathological results.

Patients with histopathologically confirmed RPOC (group 1), defined as the presence of remnants of placental trophoblastic origin, were compared with patients with negative histopathological results for RPOC (group 2). 
Table I. Patient characteristics.

\begin{tabular}{|c|c|c|c|}
\hline Characteristic & Group $1(n=32)$ & Group $2(n=21)$ & $p$-Value \\
\hline \multicolumn{4}{|l|}{ Age (years) } \\
\hline Mean \pm SD & $34.8(4.4)$ & $30.5(4.6)$ & 0.001 \\
\hline \multicolumn{4}{|l|}{ BMI $\left(\mathrm{kg} / \mathrm{m}^{2}\right)$} \\
\hline Mean \pm SD & $28.0(5.3)$ & $28.2(5.1)$ & 0.854 \\
\hline \multicolumn{4}{|l|}{ Gestational age (weeks) } \\
\hline Mean \pm SD & $37.6(3.9)$ & $36.8(3.9)$ & 0.164 \\
\hline \multicolumn{4}{|l|}{ Parity $(\%)$} \\
\hline I & 50 & 61.9 & 0.052 \\
\hline II & 37.5 & 19.0 & \\
\hline III & 9.4 & 9.5 & \\
\hline IV & 3.1 & 0 & \\
\hline \multicolumn{4}{|l|}{ Delivery mode $(\%)$} \\
\hline Caesarean section & 18.8 & 42.9 & 0.040 \\
\hline Vaginal delivery & 81.3 & 52.4 & \\
\hline \multicolumn{4}{|l|}{ Time from delivery to surgery (days) } \\
\hline Mean \pm SD & $27.4(25.2)$ & $20.9(25.3)$ & 0.382 \\
\hline Curettage & 68.8 & 76.2 & \\
\hline \multicolumn{4}{|l|}{ Surgery $(\%)$} \\
\hline Diagnostic hysteroscopy and curettage & 9.4 & 9.5 & \\
\hline Operative hysteroscopy & 15.6 & 9.5 & 0.885 \\
\hline
\end{tabular}

BIM: Body mass index. Group 1: Patients with histopathologically-confirmed retention of products of conception (RPOC); group 2: patients with negative histopathological report for RPOC; $p$-values: Mann-Whitney $U$-test for quantitative data or Fisher's exact test for qualitative data are two-sided.

All reported $p$-values (Mann-Whitney $U$-test for quantitative data or Fisher's exact test for qualitative data) are two-sided and considered statistically significant when less than 0.05 . Statistical analysis was carried out with SPSS Statistics (IBM Corp., Armonk, NY, USA).

\section{Results}

A total of 53 patients were included into this retrospective analysis. The diagnosis of RPOC was confirmed in histopathological reports of 32 cases (group 1). In total, 21 patients had a negative histopathological report for gestational tissue (group 2).

Among the patients with histopathologically confirmed RPOC, the mean age was 34.8 compared to 30.5 years in patients with negative histopathology $(p=0.001)$. The mean time from delivery to surgery was 27 days versus 21 days respectively, but did not differ significantly. Main characteristics of both groups are presented in Table I. The rate of vaginal delivery was significantly higher in group 1 with $81.3 \%$ compared to group 2 with $52.4 \%$ ( $p=0.040)$.

Among patients of group 1, 68.8\% underwent curettage, $9.4 \%$ a diagnostic hysteroscopy with combined curettage, while $15.6 \%$ of patients underwent operative hysteroscopy, which did differ significantly from that of group 2 (Table II). A sonographic intrauterine hyperechoic mass lesion was diagnosed in $84.0 \%$ in group 1 compared to $76.2 \%$ in group $2(p>0.05)$. Parameters of clinical presentation such as fever, abdominal pain and vaginal bleeding were not significantly different between the groups. These results are presented in Table III.

\section{Discussion}

In the current analysis, 52 patients with suspected RPOC were identified. According to this analysis, RPOC was proven histologically in $61.5 \%$ of patients. The results confirmed those of a prior analysis of Matijevic et al. (16), who reported a rate of $58 \%$ which stresses the complexity of diagnosis of RPOC.

Prior studies evaluated potential parameters of ultrasound as predictors of RPOC. Although endometrial thickness has been reported to be a significant predictor $(10,15,17-20)$, in our analysis, endometrial hyperechogenic mass was not appropriate for predicting RPOC. Clinical symptoms such as bleeding, pain and fever were not predictors of RPOC in our analysis, in contrast to results presented by Kamaya et al. (17). Differences in results might be explained by the difference in mean gestational age of patients analyzed, which in our study was higher compared to that of Kamaya et al. (17).

Furthermore, patient age as well as mode of delivery seem to be significant predictors of RPOC according to our results, which is in line with results of a prior study proving borderline significance for age $(p=0.06)$ and mode of delivery $(p=0.08)(21)$. 
Table II. Potential predictive parameters for retention of products of conception (RPOC).

\begin{tabular}{lccc}
\hline Characteristic & Group 1 (n=32) & Group 2 (n=21) & $p$-Value \\
\hline Prior abortion (1 abortion or more) (\%) & 25.0 & 19.1 & 0.263 \\
Prior caesarian section (\%) & 12.5 & 19.0 & 0.696 \\
Prior vaginal delivery (1 or more) (\%) & 37.5 & 23.8 & 0.380 \\
Prior curettage (1 or more) (\%) & 15.7 & 19.0 & 0.410 \\
Smoking status (\%) & & & 0.068 \\
Non smoker (\%) & 81.3 & 76.2 & 14.3 \\
Smoker (\%) & 18.8 & 4.8 & $>0.99$ \\
Gestational diabetes $(\%)$ & 6.3 & 0 & 0.315 \\
Infection with $\beta$-streptococcus $(\%)$ & 12.5 & 0 & \\
\hline
\end{tabular}

Group 1: Patients with histopathologically-confirmed RPOC; group 2: patients with negative histopathological report for RPOC.

Table III. Clinical symptoms and sonographic findings.

\begin{tabular}{lccc}
\hline Characteristic & Group 1 (n=32) & Group 2 (n=21) & $p$-Value \\
\hline Postpartum fever (\%) & 6.3 & 19.0 & 0.185 \\
Postpartum abdominal pain (\%) & 15.6 & 28.6 & 0.296 \\
Increased vaginal bleeding after delivery (\%) & 78.1 & 71.4 & 0.666 \\
Sonographic mass lesion (\%) & & & 70.99 \\
Yes & 84.4 & 76.2 & \\
No & 6.3 & 4.8 & \\
\hline
\end{tabular}

Group 1: Patients with histopathologically-confirmed retention of products of conception (RPOC); group 2: patients with negative histopathological report for RPOC.

Patients who underwent cesarean section appeared to have a reduced risk for RPOC compared to those who had a vaginal delivery due to standardized intraoperative curettage in all patients who underwent cesarean section.

\section{Conclusion}

The analysis indicates that clinical presentation alone is not predictive for RPOC. Vaginal delivery and older age seem to be risk factors for RPOC and therefore have to be considered in patients with suspected RPOC.

\section{Conflicts of Interest}

The Authors have no conflict of interest to declare in regard to this study.

\section{Ethical Approval}

All procedures performed in studies involving human participants were in accordance with the ethical standards of the institutional and/or national research committee and with the 1964 Helsinki declaration and its later amendments or comparable ethical standards.

\section{References}

1 van den Bosch T, Daemen A, Van Schoubroeck D, Pochet N, De Moor B and Timmerman D: Occurrence and outcome of residual trophoblastic tissue: A prospective study. J Ultrasound Med 27: 357-361, 2008.

2 Ganer Herman H, Kogan Z, Tairy D, Ben Zvi M, Kerner R, Ginath S, Bar J and Sagiv R: Pregnancies following hysteroscopic removal of retained products of conception after delivery versus abortion. Gynecol Obstet Invest 83(6): 586-592, 2018.

3 Melcer Y, Smorgick N, Schneider D, Pansky M, Halperin R and Ben-Ami I: Comparison of reproductive outcomes following retained products of conception after vaginal delivery versus firsttrimester abortion. Gynecol Obstet Invest 80: 206-210, 2015.

4 Russo JA, DePiñeres T and Gil L: Controversies in family planning: retained products of conception. Contraception 86 : 438-442, 2012.

5 Ben-Ami I, Ofir T, Melcer Y, Smorgick N, Schneider D, Pansky $\mathrm{M}$ and Halperin R: Infertility following retained products of conception: is it the surgical procedure or the presence of trophoblastic tissue? Eur J Obstet Gynecol Reprod Biol 182: 132-135, 2014

6 Barel O, Krakov A, Pansky M, Vaknin Z, Halperin R and Smorgick N: Intrauterine adhesions after hysteroscopic treatment for retained products of conception: what are the risk factors? Fertil Steril 103: 775-779, 2015. 
7 Tohma YA, Dilbaz B, Evliyaoğlu Ö, Çoşkun B, Çolak E and Dilbaz S: Is ultrasonographic evaluation essential for diagnosis of retained products of conception after surgical abortion? J Obstet Gynaecol Res 42: 489-495, 2016.

8 Ustunyurt E, Kaymak O, Iskender C, Ustunyurt OB, Celik C and Danisman N: Role of transvaginal sonography in the diagnosis of retained products of conception. Arch Gynecol Obstet 277: 151-154, 2008.

9 Kamaya A, Petrovitch I, Chen B, Frederick CE and Jeffrey RB: Retained products of conception: Spectrum of color Doppler findings. J Ultrasound Med 28: 1031-1041, 2009.

10 Atri M, Rao A, Boylan C, Rasty G and Gerber D: Best predictors of grayscale ultrasound combined with color Doppler in the diagnosis of retained products of conception. J Clin Ultrasound 39: 122-127, 2011.

11 de Vries JI, van der Linden RM and van der Linden HC: Predictive value of sonographic examination to visualize retained placenta directly after birth at 16 to 28 weeks. J Ultrasound Med 19: 7-12, 2000.

12 Carlan SJ, Scott WT, Pollack R and Harris K: Appearance of the uterus by ultrasound immediately after placental delivery with pathologic correlation. J Clin Ultrasound 25: 301-308, 1997.

13 Alcázar JL, Baldonado $\mathrm{C}$ and Laparte C: The reliability of transvaginal ultrasonography to detect retained tissue after spontaneous first-trimester abortion, clinically thought to be complete. Ultrasound Obstet Gynecol 6: 126-129, 1995.

14 Wong SF, Lam MH and Ho LC: Transvaginal sonography in the detection of retained products of conception after first-trimester spontaneous abortion. J Clin Ultrasound 30: 428-432, 2002.

15 Achiron R, Goldenberg M, Lipitz $S$ and Mashiach S: Transvaginal duplex Doppler ultrasonography in bleeding patients suspected of having residual trophoblastic tissue. Obstet Gynecol 81: 507-511, 1993.
16 Matijevic R, Knezevic M, Grgic O and Zlodi-Hrsak L: Diagnostic accuracy of sonographic and clinical parameters in the prediction of retained products of conception. J Ultrasound Med 28: 295-299, 2009.

17 Kamaya A, Krishnarao PM, Nayak N, Jeffrey RB and Maturen KE: Clinical and imaging predictors of management in retained products of conception. Abdom Radiol 41: 2429-2434, 2016.

18 Abbasi S, Jamal A, Eslamian L and Marsousi V: Role of clinical and ultrasound findings in the diagnosis of retained products of conception. Ultrasound Obstet Gynecol 32: 704-707, 2008.

19 Ben-Ami I, Schneider D, Maymon R, Vaknin Z, Herman A and Halperin R: Sonographic versus clinical evaluation as predictors of residual trophoblastic tissue. Hum Reprod 20: 1107-1111, 2005.

20 Betel C, Atri M, Arenson A-M, Khalifa M, Osborne R and Tomlinson G: Sonographic diagnosis of gestational trophoblastic disease and comparison withn. J Ultrasound Med 25: 985-993, 2006.

21 Kamaya A, Krishnarao PM, Nayak N, Jeffrey RB and Maturen $\mathrm{KE}$ : Clinical and imaging predictors of management in retained products of conception. Abdom Radiol 41: 2429-2434, 2016.

Received November 17, 2018

Revised December 2, 2018

Accepted December 4, 2018 